\title{
RESEARCH PAPER \\ SOCIAL SUPPORT AND ACCESS TO PRENATAL HEALTH SERVICES: A STUDY OF PREGNANT TEENAGERS IN CAPE COAST, GHANA
}

\author{
M. K. Yeboah \\ Dept of Sociology, University of Ghana, Legon, Accra
}

\begin{abstract}
:
The study examined the impact of access to social support on prenatal health seeking behavior of a selected group of pregnant teenage girls in Cape Coast, Ghana. A random sample of 170 each of pregnant teenage girls and older mothers were selected form antenatal clinic registers of three Maternal and Child Health Clinics in Cape Coast. An interview schedule was administered to seek information on initiation of prenatal visits, socio-demographic characteristics, living arrangements and access to social support. Multiple regression analysis of the data indicated that access to social support was a significant predictor of early initiation of prenatal health care, irrespective of socio-demographic background and living arrangements of the group of mothers studied. The results showed that a teenage mother-to-be with inadequate social support and living in a poor household is the standard profile of a poor initiator of early prenatal care. While the results are not very different from those obtained in other studies, notably in the United States, the implications may be more serious in a developing country like Ghana, where teenage childbearing is occurring in the context of inadequate health services, poor state sponsored social services and widespread poverty.
\end{abstract}

Keywords: teenage pregnancy, social support, pre-natal clinic visits, pregnancy outcomes.

\section{INTRODUCTION}

"...premarital pregnancy imposes great psychological and emotional strain on the unmarried but a pregnant schoolgirl who is thrust out of school, castigated by her parents, ridiculed by peers, undergoes rapid physiological and psychological changes, becomes a mother and most likely to suffer material and emotional deprivation" (Omololu, 1994; Pp 14-15)

Adolescent reproduction has long been recognized as an important issue in maternal and child health in Ghana, as in many parts of the world. This concern is underlined by the attention accorded to adolescent reproductive health issues by successive governments of Ghana, international organizations, and nongovernmental organizations.

One key medical and health issue of adolescent reproduction is its association with poor pregnancy outcomes for the mother and child. Compared to women of more mature age, pregnancy and childbearing during the teen years have been observed to present much higher risks of 
low birth weight, neonatal mortality, infant mortality and pregnancy-related medical complications (Ampofo and Gyepi-Garbrah, 1986; Babson and Clarke, 1983). In Ghana, findings from the most recent Demographic and Health Survey (2008) revealed that births to young mothers (under age 20 years) continue to be at a higher risk of dying than those of older mothers (see Table 1). socio-cultural milieu, teenage pregnancy occurs in different social contexts and it is plausible that the age and socioeconomic effects on pregnancy outcomes may also vary across cultures. In fact, when it comes to adolescent fertility, the western model which defines early childbearing in terms of out-of-wedlock births is less useful in sub-Saharan Africa, where early marriage remains common and lineage support for

Table 1: Levels of neonatal and infant mortality by age of mother, 2008

\begin{tabular}{lcc}
\hline Mother's age & $\begin{array}{c}\text { Neonatal mortality } \\
\text { (per 1000 live births) }\end{array}$ & $\begin{array}{c}\text { Infant mortality } \\
\text { (per 1000 live births) }\end{array}$ \\
\hline$<20$ & 43 & 69 \\
$20-29$ & 28 & 46 \\
$30-39$ & 35 & 60 \\
$40-49$ & 40 & $\mathbf{n} / \mathbf{a}$ \\
National & 30 & 50 \\
\hline Source: GSS: Ghana Demographic and Health Survey, 2008
\end{tabular}

\section{Explanations of Teenage Pregnancy Out- comes}

Two factors have been advanced to explain the observed link between young maternal age and the risk of adverse birth outcomes. First, births to teenagers are considered high risk due to the physical immaturity of their reproductive system, which may not be able to withstand the strains of pregnancy and childbirth (Nortman, 1974). Contrary to this biological explanation, it has been argued that the poor pregnancy outcomes associated with adolescent reproduction are due more to the disproportionate number of teenage mothers who live in poverty. According to this perspective, the effect of age on pregnancy outcomes is confounded by socioeconomic factors such as education and income (Geronimus, 1996).

These explanations are based largely on the experience of developed countries, especially the United States. It is therefore not clear if similar situation exists in less developed countries. As a biological process embedded in parenthood is still relatively strong; childbearing and childrearing in traditional African societies are rarely the exclusive concern of the biological parents (Page, 1989). For example, family members and kin, particularly mothers, grandmothers, and in-laws, have traditionally provided extensive social support for pregnant and lactating mothers (LeGrand and Mbacke, 1993). At the same time, most African societies have traditionally used social support in the form of moral, social, and economic sanctions to discourage premarital teenage pregnancy (Christensen, 1954) in order to ensure, among other things, that the mother and child have extensive social network for future support (National Research Council, 1993).

Although most adolescent childbearing in subSaharan African societies have traditionally occurred in the context of marriage and under the protection of the family, kin and community support, we are now witnessing births to teenage girls outside the protection of marriage, as a result of socio-demographic transformations 
such as increasing mobility of the youth, rapid urbanization, education and training which have not only lengthened the gap between menarche and social adulthood for adolescent girls but have also eroded the traditional strictures on adolescent sexuality. Furthermore and at the same time, these often socially stigmatized premarital pregnancies are occurring in the context of a much weakened informal supportive networks of family and kin, as well as conjugal support (Oppong, 1991; GyepiGarbrah, 1989). Thus, unlike the developed countries, there are two configurations of adolescent fertility in sub-Saharan African societies; one occurring under the protection of socially approved relationships and the other condemned and less supported outside such relationships (Bledsoe and Cohen, 1993).

This paper argues that in the context of the social dynamics of adolescent reproduction in sub -Saharan African societies, it may be access to prenatal social support, and not necessarily maternal age and/or socioeconomic status, which determines pregnancy outcomes.

The idea that the social context is important for health outcomes is not new and is clearly related to the sociological literature on social integration and isolation as first formulated by Durkheim (1954) in his classic study of suicide. Durkheim has demonstrated that the individual's social tie in the fabric of society is critical to his or her health. Persons without social tie experience a state of anomie or the feeling of isolation and loneliness which adversely affect their well-being. Contemporary social scientists have confirmed Durkheim's hypothesis by linking absence of social network and support to a variety of health outcomes (Cohen and Syme, 1986), including pregnancy outcomes (Norbeck and Tilden, 1983; Oakley, 1990; Williamson and Leferve, 1992).

\section{Theoretical Framework}

Two theoretical perspectives have been suggested in the literature regarding the specific mechanism through which social support influ- ences health outcomes. The first is the buffering hypothesis which posits that social support exerts its effects on health outcomes by protecting people from the negative consequences of stress (Cohen and Wills,1985). Stress here refers to any environmental, social, or internal demand that requires the individual to re-adjust his/her usual behavior patterns, such as the birth of the first child or divorce. In this sense, social support has meliorating influence on the underlying stressor or stressors. With regard to health outcomes, social support may motivate individuals to adopt health promoting behaviors such as proper nutrition, exercise, accessing health care and complying with treatment recommendations. The second is the direct effect hypothesis which argues that social support is an existential human need and that the absence of it may be a stressor in itself (O'Reilly, 1988). Social support, therefore, promotes good health, irrespective of the level of stress. Both direct and indirect effects of social support on health outcomes have been demonstrated in empirical research that have used various types of social support measurements (Berkman, 1985). Direct effects tend to be found when social support is measured by the degree to which individuals are integrated within social networks, while the buffering effects tend to be shown when support is measured by the availability of resources that help one to cope with stressful events.

This study makes use of both theoretical perspectives to try to understand the relationship between social support and access to health services. The study posits that maternal stress is an aetiological factor in poor pregnancy outcomes (Oakley, 1990). But the problem is likely to be intensified in adolescent pregnancy, especially if occurs outside socially recognized bounds (Omololu, 1994). Social support influences pregnancy outcomes by eliciting a positive prenatal health behavior (buffering hypothesis) and/or by directly acting as a buffer to the stress of pregnancy (direct effect hypothesis). A pregnant girl's access to prenatal health care services is hypothesized to be a function of 


\section{$71 \quad$ Yeboah}

her access to social support which is conditioned by her socio-demographic characteristics and her social network structure. These in turn are influenced by the wider socio-cultural context of values and belief systems regarding social support, as well as changes in supportive networks as a result of demographic and socioeconomic factors such as migration, urbanization, wage employment and individualism.

The objective of the paper is to assess the impact of the presence or absence of social support on prenatal health seeking behavior of a group of pregnant adolescent girls in Cape Coast in the light of a substantial body of research findings which indicates that access to adequate prenatal care may mitigate the effect of young maternal age on adverse birth outcomes (Leppert, 1986). The study is undertaken in the context of mounting evidence that the traditional structure of families, the basic systems of social support for adolescents and other family members, is undergoing rapid changes in Ghana, as in other parts of the world, with extended family networks of relatives being lost and customary patterns of social support being weakened (Araba Apt, 1990; Nukunya, 1992; Nabila and Fayorsey, 1993; Oppong, 1997).

\section{METHOD OF DATA COLLECTION}

The study was undertaken in March, 2006 at Cape Coast. The social survey research method was used to collect data for the study. The target population of interest to the study was pregnant teens aged 15 to 19 . However, older mothers between 20 and 24 years were included as a control group.

The survey population was drawn from antenatal clinic registers of three Maternal and Child Health Clinics in Cape Coast. These were the Adisadel Urban Clinic, Ewim Health Center and Cape Coast Hospital (Maternal and Child Health Unit). The health facilities were strategically located to act as catchment areas for women attending antenatal and postnatal health care within Cape Coast and its environs.
The combined list of the antenatal attendance registers from the clinics was used as the sampling frame. The sampling frame contained information of client identification number, name of mother, age of mother and home address. On the basis of information provided in the sampling frame, a random sample of 170 each of teenage mothers and older mothers were selected for the study.

\section{The Survey Instrument}

The main instrument of data collection was the questionnaire which sought to collect information on the following topics: sociodemographic background of respondents and those of their husbands/partners; maternity history; characteristics of current pregnancy; housing condition; and social support providers and resources.

The survey instrument was pre-tested to ascertain whether the concepts and language used were understood by respondents. The exercise also offered opportunity to find out about the flow and logical sequencing of questions. The pretesting was undertaken at the antenatal unit of the University of Cape Coast Hospital which was not among the health facilities selected for the study.

The administration of the instrument was of the canvassing type where respondents were visited at their homes for the interview. Two problems related to the location of respondents for interview were encountered during field work. First, poor numbering of dwelling made the location of some respondents for interview difficult. The numbering of houses in some areas were not sequential and rain had washed part of some of the house numbers. A strategy adopted to locate respondents was by probing residents of adjacent homes. Guided by the names on the sampling list, inquiries were made in these houses about any teenage girl who has recently been attending any of the selected antenatal clinics. Since such information is generally public knowledge in most Ghanaian communities, it was possible to locate some respondents in this 
manner.

Another problem was related to the proper identification of respondents at their given addresses. This was because some of the teen mothers gave incorrect addresses and/or registered at the clinics with names that were different from those by which they are called at home. Unknown to their household members, some of the teen mothers have adopted European names which are known only to friends and schoolmates. Armed with this knowledge, the strategy of snowballing was used to identify and locate respondents. By this method, teen mothers who had been successfully interviewed in a locality were used, through probing, to help locate other adolescent mothers in their area who were on the sample list. The identification number on a clinic registration card was crosschecked with that on the sample list to be certain of the true identity of a respondent who was located in this manner. The strategy proved effective and all 340 respondents sampled for the study were successfully interviewed.

\section{MEASUREMENTS AND ANALYTICAL MODEL}

A multiple regression model is employed to assess the effect of social support on prenatal health care behavior. The key assumption underlying this model is that access to social support directly affects the likelihood of a mother initiating an early prenatal visit, irrespective of her socio-demographic and household characteristics.

\section{Dependent Variable}

The dependent variable of interest is the timing of initiation of prenatal care. It is measured at two levels as early prenatal care (defined as a prenatal visit in the first trimester of pregnancy) and late prenatal care (defined as prenatal visit after the first trimester of pregnancy). An early visit may be a better and more exogenous indicator of differentials in prenatal behavior than a late visit because an early visit is less likely to be compromised by pregnancy-related problems that may necessitate seeking health care
(LeGrand and Mbacke, 1993) as well as cultural factors that may delay a visit.

\section{Independent Variables}

There is extensive literature on the sociodemographic, institutional and attitudinal barriers to prenatal care. The independent variables included in this study are maternal age (Moss and Hensliegh, 1990), maternal education (Caldwell, 1979; Elo, 1992), marital status (McCaw-Binns ,1995), religious and cultural beliefs (Brown, 1989), socioeconomic status, living arrangements and access to social support ( Caper and Hogan, 1990).

\section{Measurement of Social Support}

The concept of social support was introduced into the literature in the 1970s (Cassel, 1976; Cobb, 1976). Since then there has been tremendous increase in the number of publications that have dealt with the subject in such diverse disciplines as social psychology, sociology and health. Despite the increased interest in social support, the precise definition and measurement of the concept has eluded most researchers (Brown, 1986; Oakley, 1992).

Most investigators, however, agree that social support usually refer to the provision of instrumental, informational and emotional assistance to individuals by significant others such as the family, friends, church members, and coworkers (Vaux, 1988).

In this study social support is conceptualized as perceived support. To measure access to social support the women were asked (i) about their social network resources; (ii) kinds of assistance received (cash, clothing, food, transport, help with household task, accommodation, and emotional support) (iii) and their satisfaction with the assistance received in the two weeks before being interviewed. They choose any of two options for each type of assistance (a) as much as I would like (b) much less than I would like. A Liker-type index of satisfaction with social support received was then constructed from the responses. 


\section{Yeboah}

\section{Specification of model}

In the multiple regression equation, initiation of prenatal visit is modeled as an outcome of access to social support, individual sociodemographic characteristics and household characteristics during pregnancy. The dichotomous nature of the dependent variable is suited for use in a logistic regression model (Morgan and Teachman, 1988; Hanushek and Jackson, 1977). The specification of the model to be estimated is as follows:

$\log \left[\mathbf{P}_{\mathrm{i}} /\left(\mathbf{1}-\mathbf{P}_{\mathrm{i}}\right)\right]=\sum \boldsymbol{\beta}_{\mathbf{0}}+\boldsymbol{\beta}_{\mathrm{k}} \mathbf{X}_{\mathrm{k}}$,

where, $\mathbf{P}_{\mathbf{i}}$ is the probability that an expectant mother, $\mathrm{i}$, would initiate an early prenatal visit; $\boldsymbol{\beta}_{\mathbf{0}}$ is the intercept representing the likelihood of initiating an early prenatal visit when all coefficients are set to zero; $\boldsymbol{\beta}_{\mathbf{k}}$ is the regression coefficient for each independent variable and measures the extent to which a particular independent variable contributes to the likelihood of initiating an early prenatal visit; and $\mathbf{X}_{\mathbf{k}}$ is the independent variable whose effect is being estimated.

\section{RESULTS}

Table 2 reports on the distribution of the timing of prenatal health care visits by selected independent variables. Chi-square tests were performed to ascertain statistically significant relationships between the independent variables and the timing of prenatal visits at the 0.05 level of significance. Information in the table indicate that maternal age, marital status, education and living arrangements are all significantly associated with the likelihood of initiating an early prenatal visit. The percent use of early prenatal care is significantly lower among teenage mothers and mothers in consensual union as well as those with no education. Although not statistically significant, we note that mothers-to-be who are living with partners are better initiators of early prenatal visits than those living with parents and relatives. Similarly, pregnant schoolgirls and those in apprenticeship training have the highest percentage of early visit by work status. One would expect these groups of pregnant adolescents to be the more likely to hide their pregnancies and report late for antenatal care. The work status of other groups of women shows little variation with early prenatal visit; similar proportions of women reported an early visit among those in agriculture and the unemployed, while those in petty trading are only slightly more likely to report an early visit. Religious affiliation seems not to be significantly associated with timing of first prenatal visit.

Table 3 presents the results of three logistic regression estimates. Model 1 examines the impact of maternal age and marital status on the probability of occurrence of an early prenatal visit. Model 2 is an extension of the model to include the social support variable to examine whether its impact can account for variations in prenatal visit by maternal age and union status. Model 3 presents estimates of the likelihood of seeking early prenatal care, after controlling for other socioeconomic variables.

Overall, the results from the three models are consistent with the hypothesis that social support is significantly associated with prenatal health care behavior, although the effect of maternal age persists in all the models. Each of the models is discussed in turn.

Model 1: Results in model 1 confirm previous findings that being a teenager and being unmarried are both significantly related to poor prenatal health seeking behavior (Brown, 1989; LeGrand and Mbacke, 1990). Pregnant unmarried women and pregnant teenagers are statistically less likely to seek prenatal care in the first trimester of pregnancy compared to older and married women (reference categories).

Model 2: In this model we examine whether social support, rather than the age of the mother or her marital status, accounts for the observed variations in prenatal behavior in Model 1. The introduction of the social support variable in the model significantly improved the fit of the model. The statistical significance of the $R^{2}$ test of model fit $(p \leq 0.05)$ indicates that to underst- 
Table 2: Percent initiating prenatal care by timing of visit and selected independent variables

\begin{tabular}{|c|c|c|c|}
\hline Variable & Early Visit & Late Visit & Total No. \\
\hline \multicolumn{4}{|l|}{$\operatorname{Age}^{*}$} \\
\hline $15-19$ & 27.6 & 72.4 & 170 \\
\hline $20-24$ & 41.9 & 58.1 & 170 \\
\hline \multicolumn{4}{|l|}{ Marital Status* } \\
\hline Married & 43.0 & 57.0 & 128 \\
\hline Consensual & 29.4 & 70.6 & 151 \\
\hline Never married & 31.1 & 68.9 & 61 \\
\hline \multicolumn{4}{|l|}{ Education* } \\
\hline None & 27.4 & 72.6 & 73 \\
\hline Primary & 39.4 & 60.6 & 104 \\
\hline JHS and above & 35.2 & 64.8 & 163 \\
\hline \multicolumn{4}{|l|}{ Work Status } \\
\hline Farming/Fish seller & 30.6 & 69.4 & 36 \\
\hline Commerce & 35.6 & 64.7 & 147 \\
\hline Apprenticeship & 46.4 & 53.7 & 28 \\
\hline Student & 37.5 & 62.5 & 32 \\
\hline Unemployed & 30.9 & 69.1 & 97 \\
\hline \multicolumn{4}{|l|}{ Religion } \\
\hline Catholic & 28.6 & 71.4 & 70 \\
\hline Protestant & 38.6 & 61.4 & 125 \\
\hline Other Christian & 38.8 & 61.2 & 49 \\
\hline Moslem & 36.5 & 63.5 & 63 \\
\hline Traditional & 24.2 & 75.8 & 33 \\
\hline \multicolumn{4}{|l|}{ Ethnicity } \\
\hline Akan & 35.7 & 64.3 & 266 \\
\hline Non-Akan & 31.6 & 68.4 & 74 \\
\hline \multicolumn{4}{|l|}{ Living Arrangement* } \\
\hline Live with parent & 28.2 & 71.8 & 151 \\
\hline Live with partner & 42.2 & 57.8 & 83 \\
\hline Live with relative & 35.7 & 64.3 & 56 \\
\hline
\end{tabular}

Note: *statistically significant for $\chi^{2}$ test at $p \leq 0.05$

and the prenatal health seeking behavior of the pregnant women in our sample, it is important to know their access to prenatal social support. Results in this model demonstrate the strong and positive effect of instrumental social support on the likelihood of initiating prenatal care early in pregnancy. We further note that the significant effect of marital status on prenatal behavior observed in Model 1 disappears after controlling for social support in Model 2. This can be interpreted to mean that it is social support and not marital status per se that influence early prenatal visit. In other words when it comes to making an early prenatal visit, it does not matter if a woman is married or not as long as she receives adequate social support. However, contrary to expectation, it does matter if the mother is a teenager. This is because the expected non-significance of the effect of maternal age on early prenatal visit, after account- 


\section{Yeboah}

Table 3: Logistic regression results describing the relationship between social support and early initiation of prenatal visit.

\begin{tabular}{|c|c|c|c|c|c|c|}
\hline \multirow[t]{2}{*}{ Independent Variable } & \multicolumn{2}{|c|}{ Model 1} & \multicolumn{2}{|c|}{ Model 2} & \multicolumn{2}{|c|}{ Model 3} \\
\hline & Coef. & $\mathrm{z}$ & Coef. & $\mathrm{z}$ & Coef & $\mathrm{z}$ \\
\hline Marital Status & & & & & & \\
\hline Consensual & $-0.51 *$ & -1.99 & -0.39 & -1.50 & -0.42 & -1.37 \\
\hline Never married & -0.29 & -0.82 & -10.19 & -0.56 & -0.17 & -0.47 \\
\hline Age & & & & & & \\
\hline $15-19$ & $-0.57 *$ & -2.35 & $-0.60^{*}$ & -2.46 & $-0.47 *$ & -1.98 \\
\hline Social Support & & & & & & \\
\hline Instrumental & & & $0.26^{*}$ & 2.10 & $0.28^{*}$ & 2.08 \\
\hline Education & & & & & & \\
\hline No education & & & & & -0.21 & -.06 \\
\hline Primary & & & & & 0.23 & 0.80 \\
\hline Work Status & & & & & & \\
\hline Farming/Fishing & & & & & -0.13 & -0.32 \\
\hline Student & & & & & 0.30 & 0.86 \\
\hline Unemployed & & & & & -1.10 & -0.34 \\
\hline Ethnicity & & & & & & \\
\hline Akan & & & & & 0.29 & 0.92 \\
\hline Religion & & & & & & \\
\hline Catholic & & & & & 0.01 & 0.02 \\
\hline Protestant & & & & & 0.58 & 1.17 \\
\hline Other Christian & & & & & 0.40 & 0.73 \\
\hline Moslem & & & & & & \\
\hline Living Arrangement & & & & & & \\
\hline With parents & & & & & -0.20 & -0.68 \\
\hline With partner & & & & & -0.19 & -0.52 \\
\hline SES & & & & & & \\
\hline $\begin{array}{l}\text { Dwelling raffia/thatched } \\
\text { roof }\end{array}$ & & & & & $-1.58 *$ & -3.02 \\
\hline CONSTANT & -0.09 & -0.45 & -0.15 & -0.76 & 1.07 & 0.19 \\
\hline Pseudo $R^{2}$ & 0.026 & & $0.037 *$ & & 0.087 & \\
\hline
\end{tabular}

Note: Reference category for union status is married, for age is older mother, for education is JHS, for work status is commerce, for ethnicity is non-Akan, for religion is traditional, for socioeconomic status (SES) is high. $* P \leq 0.05$.

ing for social support in this model did not appear. This suggests that there is something about being an expectant teenager that acts as barrier to seeking prenatal care early in pregnency, once marital status and social support are accounted for. A possible explanation may be that in traditional Ghanaian societies it is regarded immodest for a pregnant woman, especially a primipara, to publicly disclose her early pregnancy status. Thus this behavior may have more to do with socio-cultural reasons than maternal age. Another probable reason may be the fear of disclosure of pregnancy to significant others (Brown, 1989), particularly if 
the pregnancy occurred outside socially approved context.

Model 3: The model shows that the significant effects of maternal age and social support on the timing of prenatal health care visit persist after controlling for potential rival covariates. The only other significant factor that affects early prenatal behavior in this model is the socioeconomic status of the household of which the pregnant woman is a member. Women from poor households (measured by raffia roofing) are significantly less likely to report for early prenatal care than their sisters living in high income households (measured by aluminum/tile roofing). This result is expected as poverty is often associated with low education and low income both of which are also associated with poor health seeking behavior.

Maternal education, work status, religion, ethnicity, and living arrangements were poor predictors of early initiation of prenatal care. In fact an $R^{2}$ test of model fit indicated that including these variables did not significantly improve the fit of the model ( $p=0.153)$. This suggests that a model without these covariates explains the variance in prenatal care behavior just as well as a model with these covariates.

\section{CONCLUSIONS}

As a group, pregnant adolescent girls are more likely than older women to receive inadequate prenatal health care services (Leppert, 1986). These behaviors have been hypothesized to lead to poor birth outcomes for adolescent mothers and their children (McCaw-Binns, 1995). In this paper we examined, through multivariate analysis, the possibility that social support influences in part the observed poor access to prenatal health care in teenage pregnancy. Specifically, the analysis focused on whether social support independently influences prenatal health care behavior in pregnancy. The analysis identified three factors that acted as barriers to the initiation of early prenatal care among the prospective mothers studied. These were young maternal age, lack of social support and poverty. The analysis revealed that a teenage mother with inadequate social support and living in a poor household is the standard profile of a poor initiator of early prenatal care in the group studied. While the result is not very different from those obtained in other studies, notably in the United States (Geronimus, 1996), the implication may be more serious in a developing country such as Ghana, where teenage childbearing is occurring in the context of inadequate health services, weak state sponsored social welfare services and widespread poverty.

\section{REFERENCES}

Ampofo, D. A. and Gyepi-Garbrah, B. (1986). Dimensions of adolescent pregnancy at Korle -Bu Teaching Hospital. Paper presented at the National Conference on Population and National Reconstruction held at University of Ghana, Legon, April,7-10, 1986.

Araba Apt, N. (1993). Care of the elderly in Ghana: An emerging issue. Journal of Crosscultural Studies, 8 (1): 301-312.

Babson, S. G. and Clarke, N. G. (1983). Relationship between infant death and maternal age: comparison of sudden death incidence with other causes of infant mortality. Journal of Pediatrics, 103: 391-303.

Berkman, L. G. (1985). The relationship between social support and health in S. Cohen and L.S Syme (eds). Social Support and Health, Academy Press, New York.

Bledsoe, C. and Cohen, B. (1993). Social dynamics of adolescent fertility in sub-Saharan Africa. National Academy Press, Washington, DC.

Brown, M. A. (1986). Social support during pregnancy: A unidimensional or multidimensional construct?. Nursing Research; 35 (1): 4-9

Brown, S. S. (1989). Drawing women into pre- 
natal care. Family Planning Perspective; 21 (2): 73-80.

Caldwell, J. C. (1979). Education as a factor in mortality decline: an examination of Nigerian data. Population Studies, 33:395-413.

Casper, L. M. and Hogan, D. P. (1990). Family networks in prenatal and postnatal health. Social Biology, 37 (1-2):84-101.

Cassel, J. (1976). The contribution of social environment to host resistance. American Journal of Epidemiology, 104: 107-123

Christensen, J. B. (1954). Double descent among the Fanti. Human Relations Area Files, New Haven, U.S.A

Cobb, S. (1976). Social support as moderator of life stress. Pychosomatic Medicine, 38: 300-314

Cohen, S. and Wills, T. A. (1985). Stress, social support and the buffering hypothesis. Psychological Bulletin, 98: 310-357

Durkheim, E. and Simpson, G. (eds). (1951). Suicide: A study in Sociology. The Free Press, Glenwe, Illinois.

Elo, I. (1992). Utilization of maternal and child health care services in Peru: The role of women education. Health Transition Review, 2: 46-69.

Geronimus, A. T. (1996). Black/white differences in the relationship of maternal age to birth weight: A population-based test of the weathering hypothesis. Social Science \& Medicine, 42 (4): 589-597.

Ghana Statistical Service and ICF Macro. (2009). Demographic and Health Survey 2008. Accra and Calverton, Maryland.

Gyepi-Garbrah, B. (1985). Adolescent Fertility in sub-Sahara Africa. The Pathfinder Fund,
New York

Hogan, D. P. and Kitagawa, F. M. (1985). The impact of social status, family structure and neighborhood on fertility of adolescents. American Journal of Sociology, 90: 825-855.

LeGrand, T. K. and Mbacke, C. S. M. (1993). Teenage pregnancy and child health and child mortality in urban Sahel. Studies in Family Planning, 24 (3): 137-49.

Hanushek, E. and Jackson, J. (1977). Statistical Methods for Social Scientists. Academic Press, New York.

Leppert, P. C. (1986). Pregnancy outcomes among adolescent and older mothers receiving comprehensive prenatal care. Journal of Adolescent Health Care, 7 (2): 112-117

Llyod, C. B. (1994). Adolescent fertility in sub -Saharan Africa. Population and Development Review, 20 (1): 194-9.

McCaw-Binns, A. (1995). Under users of antenatal care: A comparison of non-attenders and late attenders for antenatal care with early attenders, Social Science \& Medicine, 40(7): 1003-1012

Morgan, S. P. and Teachman, J. D. (1988). Logistic regression: Description, examples and comparisons. Journal of Marriage and the Family,50: 929-936.

Moss, N. E. and Hensleigh, P. A. (1990). Initiation of prenatal care by adolescents: Association with social support, stress and Hispanic ethnicity. Journal of Perinatal, 10 (2): 170-4.

Nabila, J. S. and Fayorsey, C. (1995). Adolescent fertility and reproductive behavior in Ghana: A case study of Accra and Kumasi. Family and Development Programme $(F A D E P)$, University of Ghana, Legon, Accra. 
Norbeck, J. S. and Tilden, V. P. (1983). Life stress, social support and emotional disequilibrium in complications of pregnancy: A prospective multivariate study. Journal of Health and Social Behavior, 24: 30-46.

Nortman, T. (1974). Parental age as a factor in pregnancy outcome and child development. Population and Family Planning, vol. 16

National Research Council (1988) Contraception and Reproduction: Health Consequences for Women and Children in Developing Countries, National Academy Press, Washington, D.C.

Nukunya, G. K. (1992). Tradition and Change in Ghana: An Introduction to Sociology. Ghana Universities Press, Accra.

Oakley, A. (1990). Social support and pregnancy outcomes. British Journal of Obstetric and Gynecology, 95: 155-162.

Omololu, F.( 1994). Adolescent childbearing and poverty: identifying the mechanisms for creation and transmission of poverty in south western Nigeria. Paper presented at IUSSP Seminar on Women, Poverty, and Demographic Change, Mexico, 25-28 October, 1994

Oppong, C. (1991). Conjugal and parental rol- es in African families: Old and new models. Paper presented for the session on Dynamics of Family Systems and Changes in Family Roles. Third World, Third Conference of the Union of African Population Studies, Ouagadougou; April, 1991

Oppong, C. (1997). Smiling infants and crying babies: Taking reproductive labor and maternal strain into account in sustainable development framework, policies and plans. Paper presented at the Watson Institute, Brown University, Nov. 1997.

O'Reilly, P. (1988). Methodological issues in social support and social network research. Social Science \& Medicine, 26 (8): 863-873

Page, H. (1989). Childbearing versus childrearing: co-residence of mother and children in sub-Saharan Africa in R.I. Lesthaeghe (ed). African Reproduction and Social Organization, University of California, Berkley

Vaux, A. (1988). Social Support: Theory, Research and Interventions. Praeger Publishers, New York

Williamson, H. A and Lefevre, M. (1992). roles in African families: Old and new modTangible assistance: A simple measure of social support predicts pregnancy outcomes. Family Practice Research Journal, 12 (3): 289-95 